\title{
About the series
}

\section{Professor Robert Solow}

The Cournot Centre for Economic Studies is an independent French-based research institute. It takes its name from the pioneering economist, mathematician and philosopher Antoine Augustin Cournot (1801-77).

Neither a think-tank nor a research bureau, the Centre enjoys the special independence of a catalyst. My old student dictionary (dated 1936) says that catalysis is the 'acceleration of a reaction produced by a substance, called the catalyst, which may be recovered practically unchanged at the end of the reaction'. The reaction we have in mind results from bringing together (a) an issue of economic policy that is currently being discussed and debated in Europe and (b) the relevant theoretical and empirical findings of serious economic research in universities, think-tanks and research bureaux. Acceleration is desirable because it is better that reaction occurs before minds are made up and decisions taken, not after. We hope that the Cournot Centre can be recovered practically unchanged and used again and again.

Notice that 'policy debate' is not exactly what we are trying to promote. To have a policy debate, you need not only knowledge and understanding, but also preferences, desires, values and goals. The trouble is that, in practice, the debaters often have only those things, and they invent or adopt only those 'findings' that are convenient. The Cournot Centre hopes to inject the findings of serious research at an early stage.

It is important to realize that this is not easy or straightforward. The analytical issues that underlie economic policy choices are usually complex. Economics is not an experimental science. The available data are scarce, and may not be exactly the relevant ones. Interpretations are therefore uncertain. Different studies, by uncommitted economists, may give different results. When those controversies exist, it is our hope that the Centre's conferences will discuss them. Live debate at that fundamental level is exactly what we are after.

This particular conference is unique to the Series. Here the contribution and continued relevance of the Centre's namesake, Augustin Cournot, is debated and elaborated. While this has the advantage of avoiding questions of short-term applicability, it is less evident what impact the subject may have on decision- 
making processes or policy issues. Nevertheless, the subject has great relevance to the Centre's work.

Augustin Cournot's pluridisciplinary vision and approach are reflected in the Centre's activities. We all know Cournot's role in the development of mathematical modelling, industrial economics and game theory in the field of economics. It is less known, however, that Cournot's interests and contributions extended also to the fields of philosophy, history - in particular the history of philosophy - and, more generally, to the social sciences. Although it took sometimes several decades after his death for economists to begin to take notice of his knowledge and intuitions, Cournot has provided immeasurable inspiration to his successors the world over. Emphasizing the theoretical, economic and mathematical lineage from Cournot to the Centre focuses and highlights its work, inscribing the Centre's activities as part of Augustin Cournot's legacy.

I used the words 'serious research' a moment ago. That sort of phrase is sometimes used to exclude unwelcome ideas, especially unfashionable ones. The Cournot Centre does not intend to impose narrow requirements of orthodoxy, but it does hope to impose high standards of attention to logic and respect for facts. It is because those standards are not always observed in debates about policy that an institution like the Cournot Centre has a role to play. 